\title{
Challenges in the Australasian neurosurgery training program: who should be trained and where should they train?
}

\author{
Katharine J. Drummond, MBBS, MD, FRACS, ${ }^{1,2}$ Benjamin H. M. Hunn, BMedSc, MBBS, DPhil, ${ }^{1}$ \\ Heidi E. McAlpine, BSc, MBBS, ${ }^{1}$ Jordan J. Jones, MBBS, ${ }^{1,2}$ \\ Mark A. Davies, MBBS, LLM (Medical Law \& Ethics), FRACS, ${ }^{3,4}$ and Stacie Gull, MBUS, MBA ${ }^{5}$
}

1Department of Neurosurgery, The Royal Melbourne Hospital, Parkville, Victoria; ${ }^{2}$ Department of Surgery, University of Melbourne, Parkville, Victoria; ${ }^{3}$ Department of Neurosurgery, St George Hospital, Kogarah, New South Wales; ${ }^{4}$ Faculty of Medicine, University of New South Wales, Kensington, New South Wales; and ${ }^{5}$ Neurosurgical Society of Australasia, Melbourne, Victoria, Australia

OBJECTIVE Neurosurgical training poses particular challenges in Australia and New Zealand, given the large landmass, small population, and widely separated, often small, neurosurgical units. Such factors have necessitated a move away from autonomous, single-institution-based training to the selection of trainees by a centralized binational process. The success of this system is based on rigorous standardized evaluation of candidates' academic achievements, anatomical knowledge, references, and interview performance. Similarly, the accreditation of hospitals to train successful candidates has been standardized. The authors review the evolution of trainee selection and the accreditation of training posts in Australia and New Zealand.

METHODS The records of the Neurosurgical Society of Australasia Surgical Education and Training Board were reviewed for documents pertaining to the selection of neurosurgical trainees and the accreditation of training posts. Application records and referee scores from 2014 to the present were reviewed to encompass process changes, in particular the change from written referee reports to standardized interviews of referees. Surgical logbook case numbers for 23 trainees completing training in 2016, 2017, and 2018 were collated and presented in an aggregated, de-identified form as a measure of adherence to accreditation standards. Written evaluations of the training experience were also sought from two trainees reflecting on the selection process, the quality of training posts, and training limitations.

RESULTS While a time-consuming process, the method of obtaining referee reports by interview has resulted in a wider spread of scores, more able to separate high- and low-scoring applicants than other components of the selection process. Review of the training post accreditation records for the last 2 years showed that adherence to standards has resulted in loss of accreditation for one unit and shortened periods of review for units with more minor deficiencies. Two applications for accreditation have been denied. Examination of caseload data showed that trainees more than fulfill minimum requirements in accredited training posts, confirming the robust nature of this aspect of unit accreditation.

CONCLUSIONS A key factor determining the success of neurosurgical training in Australia and New Zealand has been a willingness to evolve selection and other processes to overcome challenges as they become apparent. According to available analyses, the revised referee process and strict accreditation standards appear effective. The benefits and challenges of the current training system are discussed in the context of a paucity of international literature.

https://thejns.org/doi/abs/10.3171/2019.12.FOCUS19870

KEYWORDS neurosurgery; education; training; selection; Australia; New Zealand

$\mathrm{W}$ HILE there is ample recent literature on both innovative educational methods in neurosurgery, particularly simulation and virtual reality, $2,3,7,12,14,15$ and the importance of research within neurosurgical training, ${ }^{5,6}$ there is relatively less attention to two arguably more important aspects of producing excellent neurosurgeons, that is, the selection of trainee s $^{1,2,17}$ and the accreditation of training units or programs. ${ }^{4,8,10}$ Given the unique training environment in Australia and New Zealand, these aspects of neurosurgical education have recently come under close scrutiny.

ABBREVIATIONS CV = curriculum vitae; NSA = Neurosurgical Society of Australasia; RACS = Royal Australasian College of Surgeons; SET = Surgical Education and Training.

SUBMITTED November 4, 2019. ACCEPTED December 16, 2019.

INCLUDE WHEN CITING DOI: 10.3171/2019.12.FOCUS19870. 
Australia is a large country with a relatively small population of approximately 25 million people. Neurosurgical units are generally located in the major cities, which lie on the coast, some widely separated and servicing relatively small populations. A similar situation exists in New Zealand, though more because of population size (just under 5 million people) than distance.

In the late 1980s, the training board of the Neurosurgical Society of Australasia (NSA) determined that many smaller single neurosurgical units in Australia and New Zealand could not provide the breadth of experience and caseload required for adequate training of neurosurgeons. This led to the formulation of a centralized binational training program between 1991 and 1994 under the leadership of Professor Peter Reilly, with trainees moving between neurosurgical units every 1 or 2 years, with at least one interstate or international allocation. Most trainees would rotate through 3 or 4 training units, with the benefit of training and mentorship by 20 or more individual neurosurgeons, which would not be possible in a single smaller unit. Trainees were selected centrally as part of a binational program. Central accreditation of training posts by the NSA board had already been instituted under the previous board chair, Professor Leigh Atkinson, and this informed the need for rotation through a number of training units for a broad and adequate training experience. Neurosurgical training in Australia and New Zealand has subsequently undergone a number of evolutions. The curriculum has been reviewed regularly (with a major review in $2005^{11}$ and an another planned for 2020), training has been lengthened from 4 to 5 or 6 years and subsequently evolved to competency-based training with the possibility of flexible working hours, and regular in-training assessments have been added to the long-standing exit examination.

Despite the general satisfaction with this method of training, specific challenges are related to this centralized system. The first is the selection of applicants for training. There has never been a rigorous evaluation of neurosurgery (or any other surgical specialty) trainee selection, and no superior method has been agreed upon. ${ }^{1,2,17}$ In the Australasian system, the choice of trainees by a binational central selection panel, with subsequent allocation of that trainee to rotation through a number of training units, has led to much discussion, particularly when an underperforming trainee is recognized. While the selection process (discussed below) is arduous and transparent, not all trainees complete training, and disciplinary proceedings due to poor performance, even late in training, are not uncommon. Whether such outcomes are attributable to poor selection processes or a lack of "skin in the game" for each training unit is not clear. For instance, if a particular unit does not take "ownership" of a trainee from the time of appointment to the end of training and early independent practice, then it may be more straightforward to give an excellent reference or pass a trainee in a placement to allow them to move to the next step, rather than to take the more difficult and sometimes adversarial or litigious path of giving genuine negative feedback and/or refusing to give a reference or even fail a trainee in a placement.

Similarly, if trainees, and often their families, are to
TABLE 1. Weighting of the components of the selection process for applicants to neurosurgery training in Australia and New Zealand

\begin{tabular}{lcc}
\hline \multicolumn{1}{c}{ Component } & Weighting & Satisfactory Performance \\
\hline Structured CV & $15 \%$ & $50 \%$ (5.5 of 11 possible) \\
\hline Neurosurgery anatomy exam & $30 \%$ & $70 \%$ \\
\hline Referee report & $30 \%$ & $50 \%$ (36 of 72 possible) \\
\hline $\begin{array}{l}\text { Neurosurgery semistructured } \\
\text { interview }\end{array}$ & $25 \%$ & $50 \%$ (8 of 16 possible) \\
\hline
\end{tabular}

be moved long distances between training units and as trainee experience rightly becomes more appreciated, the quality of training posts is paramount. Thus, the minimum characteristics for accreditation of a neurosurgical unit as a training post have been strictly defined, and regular feedback is sought from trainees on their experience in each post.

In this paper, we discuss the evolution of these two important aspects of neurosurgical training-selecting who should train and where they should train.

Trainees in neurosurgery in Australia and New Zealand are selected by the Surgical Education and Training (SET) Board of the NSA. In many respects, selection is similar to that in other international neurosurgical programs. Selection includes analysis of a structured curriculum vitae $(\mathrm{CV})$, including previous research and publications. A major component of the $\mathrm{CV}$ is also previous neurosurgical experience, as Australasian medical graduates enter neurosurgical specialty training after an internship and a period of prevocational training in which they gain experience in a number of specialties. A minimum standard for the CV must be attained, and the applicant must sit for a 70-question, multiple-choice neurosurgery anatomy examination. Satisfactory performance according to the $\mathrm{CV}$ and on the examination will lead to reference checks from three referees, and the 24 highest-scoring applicants on these first three components are subsequently selected for the final semistructured interviews, all of which are standardized clinical scenario interviews with defined marking rubrics. The weighting of each component of the selection process is shown in Table 1.

Of these components, the most contentious over the previous 10 years has been the referee report. The experience of the SET Board and other authors $\mathrm{s}^{1,17}$ has been that standard written references, using either a pro forma reference or letter of recommendation, did not discriminate between applicants, with many candidates submitting pro forma references with perfect scores or overly positive written references, neither of which reflected subsequent performance in training. We report the early results of a change in practice from a pro forma written reference to a detailed telephone interview with three referees for each trainee considered for selection. We also report on the standardized central accreditation process for training posts in the context of the trainee experience and surgical caseload.

\section{Methods}

The records of the SET Board of the NSA were re- 
TABLE 2. RACS competencies of a surgeon that underpin the SET program in neurosurgery in Australia and New Zealand

\begin{tabular}{ll}
\hline \multicolumn{1}{c}{ Competency } \\
\hline Medical expertise \\
\hline Technical expertise \\
\hline Judgment, decision-making \\
\hline Collaboration \& teamwork \\
\hline Communication \\
\hline Health advocacy \\
\hline Management \& leadership \\
\hline Professionalism \\
\hline Scholarship \& teaching
\end{tabular}

viewed for documents pertaining to the selection of neurosurgical trainees and the accreditation of neurosurgical training posts. Training records from 2014 to the present were reviewed to encompass key changes in the process. With the consent of the SET Board, these data were extracted in a de-identified fashion; the majority of the information is publically available, and no institutional review board approval was necessary. Additionally, historical data pertaining to the evolution of the current Australasian system were obtained from SET Board archives back to 2000 and from interviews with Professors Peter Reilly and Andrew Kaye, previous training board chairs.

\section{Change to Referee Reports Using Semistructured Interviews}

Scores for components of applications to neurosurgical training between 2014 and 2019 were collected, and referee scores were compared for the assessment of changes in the process. Average scores for the referee section of the application process as well as ranges were compared. In 2015, referee reports were no longer obtained using a written pro forma reference but rather through a semistructured interview with three neurosurgeons, usually in different neurosurgical units, who had recently worked with the applicant. The applicant does not choose the referees specifically but identifies recent supervisors, and the SET Board can choose to interview any neurosurgeon who has recently worked with the applicant. The reference interview is undertaken by two neurosurgeon members of the Board, with a member of the executive staff preparing notes of the discussion and recording scores. The components of each interview are collated into a final score. The reference interview follows a basic script with questions for further probing of answers, and a marking rubric is supplied.

The referee report script includes the following components, each with multiple questions, to assess the 9 competencies of a surgeon as outlined by the Royal Australasian College of Surgeons (RACS; Table 2).

\section{Context}

The interviewer determines the relationship of the referee to the applicant, including period of contact and in what capacity and circumstances.

\section{Technical Skills}

The interviewer determines the applicant's level of surgical competence in common basic neurosurgical procedures. Questions relate to dexterity, orderly flow of technique, positioning, dealing with complications, and evidence of preparatory study. The level of supervision required is also explored, as is the ability to work under pressure.

\section{Collaboration and Teamwork, Medical Expertise, and Judgment}

The interviewer determines the quality of the applicant's patient care, including the trustworthiness of assessments, recognition of complications, organization, punctuality, and communication skills. Interactions with nursing, the Emergency Department, and intensive care unit staff are explored.

\section{Communication and Professionalism}

The interviewer determines whether the applicant's communication is precise, relevant, and accurate to both senior and junior staff and patients and whether they might ever be perceived as rude, dismissive, or abrupt. Professional behavior such as ease of contact, reliability, workload management, and honesty in all communications is explored, as is a mature response to mistakes and negative feedback, with a particular emphasis on taking personal responsibility and not blaming others.

\section{Scholarship, Teaching, and Readiness for Training}

The interviewer determines whether the applicant attends mandated educational sessions and their levels of contribution and enthusiasm. The referee is then questioned about whether the applicant is ready for trainingor would benefit from further prevocational experience before formal training.

\section{Accreditation of Training Posts and Trainee Experience}

The accreditation of training posts for excellence is critical to the success of the training experience. In accordance with RACS policy, training posts are accredited every 5 years by the SET Board, although shorter periods of accreditation can be given if deficiencies must be rectified. Accreditation involves site visits with physical inspection; interview of trainees, neurosurgeons, and other staff; and review of application documents. Accreditation can involve a single site or, commonly, 2 or 3 collaborating sites with a primary site taking overarching responsibility. For instance, many large tertiary neurosurgical centers have secondary community hospitals or a private hospital in proximity, which acts as a collaborating training site. Trainees are allocated to the primary site but can spend up to $20 \%$ of their time at the secondary sites. Each primary site must have a designated neurosurgical supervisor of trainees for whom there are strict professional and training requirements. Appointment of a neurosurgical supervisor can be reviewed or revoked by the SET Board at any time.

The accreditation standards are outlined in Table 3 and include considerations of caseload and casemix, hospital facilities, training infrastructure, and, more recently, a strong emphasis on trainee welfare, including robust 
TABLE 3. A summary of the NSA SET Board training post accreditation standards

\begin{tabular}{|c|c|c|}
\hline Standard & Theme & Principles \\
\hline 1 & $\begin{array}{l}\text { Hospital w/ a culture } \\
\text { of respect for } \\
\text { patients \& staff }\end{array}$ & $\begin{array}{l}\text { Policies, procedures, \& staff education to provide safe training environment free of discrimination, bullying, \& sexual } \\
\text { harassment, actively promoting teamwork \& professionalism } \\
\text { Policies \& guidelines aligned w/ RACS Code of Conduct } \\
\text { Commitment to share complaint \& misdemeanor information w/ SET Board } \\
\text { Robust complaint management \& performance review processes }\end{array}$ \\
\hline 2 & $\begin{array}{l}\text { Education facilities } \\
\text { \& systems }\end{array}$ & $\begin{array}{l}\text { Computer facilities, internet access, \& tutorial rooms } \\
\text { Private study areas isolated from busy clinical areas }\end{array}$ \\
\hline 3 & $\begin{array}{l}\text { Quality education, } \\
\text { training, \& learn- } \\
\text { ing }\end{array}$ & $\begin{array}{l}\text { Coordinated schedule of education w/o conflicting obligations; } 4 \text { hrs of structured neurosurgeon-led tutorials, } 1 \\
\text { neuropathology session, } 1 \text { Journal Club, \& } 4 \text { hrs neuroradiology sessions per month } \\
\text { Access to simulated learning \& basic skills training equipment } \\
\text { Educational leave to attend compulsory courses, scientific meetings, biannual trainee seminars, \& exams } \\
\text { Opportunity to participate in research } \\
\text { Supervised management of patients in ED accredited by Australasian College of Emergency Medicine or equivalent; } \\
\quad \& \text { ICU accredited by Australian \& New Zealand College of Anaesthetists or equivalent }\end{array}$ \\
\hline 4 & $\begin{array}{l}\text { Neurosurgical train- } \\
\text { ing supervisors } \\
\text { \& staff }\end{array}$ & $\begin{array}{l}\text { Neurosurgical training supervisor satisfies requirements of RACS Surgical Supervisors Policy \& NSA Training } \\
\text { Program Regulations, w/ a fellowship in neurosurgery from RACS, membership of NSA, compliant w/ RACS } \\
\text { Continuing Professional Development requirements \& spending a min of } 20 \mathrm{hrs/wk} \text { at training site } \\
\text { Additional neurosurgical trainers who satisfy all responsibilities \& requirements outlined above but w/ less time } \\
\text { commitment: for training post w/ } 1 \text { trainee, a min of } 2 \text { additional neurosurgical trainers spending a combined min } \\
\text { total of } 40 \mathrm{hrs/wk} \mathrm{in} \mathrm{the} \mathrm{site;} \mathrm{for} \mathrm{training} \mathrm{post} \mathrm{w/} 2 \text { trainees, a min of } 3 \text { additional neurosurgical trainers spending a } \\
\text { combined min total of } 60 \mathrm{hrs/wk} \mathrm{in} \mathrm{the} \mathrm{site;} \mathrm{for} \mathrm{training} \mathrm{post} \mathrm{w/} 3 \text { trainees, a min of } 4 \text { additional neurosurgical train- } \\
\text { ers spending a combined min total of } 90 \mathrm{hrs/wk} \mathrm{in} \mathrm{the} \mathrm{site} \\
\text { Neurosurgical supervisor \& trainers should discuss \& agree on goals for trainee \& provide one-to-one clinical su- } \\
\text { pervision, frequent informal feedback, structured constructive feedback, \& recorded assessment of performance; } \\
\text { trainee must have opportunity to respond to feedback } \\
\text { Paid, protected administrative time \& secretarial \& IT services to undertake neurosurgical supervisor duties, \& nego- } \\
\text { tiated leave to attend mandated training \& meetings }\end{array}$ \\
\hline 5 & $\begin{array}{l}\text { Support services for } \\
\text { trainees }\end{array}$ & $\begin{array}{l}\text { Work schedules that adhere to local legislation } \\
\text { Trainees on-call } \leq 1 \text { day in } 3 \text {; work < } 70 \text { hrs/wk; be safe \& have security provided when necessary; have access to } \\
\text { Human Resources services, including counseling if required } \\
\text { Remuneration in accordance w/ public sector awards; commitment to facilitate flexible (part-time or interrupted) employ- } \\
\text { ment }\end{array}$ \\
\hline 6 & $\begin{array}{l}\text { Clinical load \& oper- } \\
\text { ating sessions }\end{array}$ & $\begin{array}{l}\text { Min of } 1 \text { outpatient clinic per wk to see new \& FU patients under supervision } \\
\text { Defined neurosurgical inpatient unit of sufficient beds (min } 15 \text { ) to enable adequate turnover } \\
\geq 3 \text { ward rounds or patient care meetings per wk w/ a neurosurgeon } \\
\text { Min no. of major neurosurgical procedures required annually-adult posts: for } 1 \text { trainee, } 400 \text { major cases w/ min of } \\
200 \text { in primary site; for } 2 \text { trainees, } 600 \text { major cases w/ min of } 300 \text { in primary site; for } 3 \text { trainees, } 900 \text { major cases } \\
\text { w/ min of } 450 \text { in primary site; pediatric posts: for } 1 \text { trainee, } 200 \text { major pediatric neurosurgical cases } \\
\text { Significant hands-on involvement in surgical cases, increasing based on skill level to primary surgeon } \\
\text { Participation in min of } 100 \text { major neurosurgical cases per } 6 \text { mos in adult posts \& } 75 \text { in pediatric posts } \\
\text { Major involvement in periop management of patients } \\
\text { Regular weekly involvement in acute/emergency care of neurosurgical patients, w/ min 1:5 involvement in emergency } \\
\text { care required }\end{array}$ \\
\hline 7 & $\begin{array}{l}\text { Equipment \& clinical } \\
\text { support services }\end{array}$ & $\begin{array}{l}\text { Accreditation of sites by Australian or New Zealand Councils of Healthcare Standards to undertake surgical care } \\
\text { Suitable diagnostic \& intervention services, including } 24 \text {-hr, } 7 \text {-day access to CT, DSA, MRI, \& general pathology } \\
\text { Additional specialist neuropathology access } \\
\text { Framed \& frameless stereotactic equipment, operating microscope, \& ultrasonic aspirator } \\
\text { Support \& ancillary services including rehabilitation, neuropsychology, neuropsychiatry, neurology, \& radiology; } \\
\quad \text { secretarial support; \& office space }\end{array}$ \\
\hline 8 & $\begin{array}{l}\text { Clinical governance } \\
\text { quality \& safety }\end{array}$ & $\begin{array}{l}\text { Quality assurance board or equivalent (w/ senior external member) reporting to a governance body \& documentation } \\
\text { published by hospital on human resources, clinical risk management, \& other safety policies } \\
\text { Designated head of neurosurgical department w/ a defined role in governance \& leadership \& department meetings } \\
\text { a min of every } 6 \text { mos in each site } \\
\text { All medical staff credentialed at least every } 5 \text { yrs in all sites by hospital credentialing committee } \\
\text { Regular (at least quarterly) review meetings of morbidity/mortality, averaging } 1 \mathrm{hr} / \mathrm{mo} \mathrm{w} / \text { all neurosurgical supervi- } \\
\text { sors, trainers, \& trainees participating \& w/ robust peer review }\end{array}$ \\
\hline
\end{tabular}

$\mathrm{ED}=$ Emergency Department; $\mathrm{FU}$ = follow-up; ICU = intensive care unit; min = minimum. 
TABLE 4. Number of applicants for neurosurgery training in Australia and New Zealand in 2019 and their performance on components of the selection process

\begin{tabular}{ccccc}
\hline Variable & CV & Anatomy Exam & Referee Report & Interview \\
\hline Applicants scored & 66 & 66 & $54^{*}$ & $24(6$ females [25\%]) \\
\hline No. passed female & $15(22.7 \%)$ & $14(21.2 \%)$ & $11(20.4 \%)$ & NA \\
\hline No. passed male & $48(72.7 \%)$ & $44(66.7 \%)$ & $36(66.7 \%)$ & NA \\
\hline
\end{tabular}

NA = not applicable.

* One applicant withdrew following the CV and examination steps. Of $66 \mathrm{CVs}$ scored, only 63 applicants obtained sufficient points to be considered further. Of the 66 applicants who sat for the anatomy exam, only 58 obtained a passing mark, leaving 54 applicants proceeding to referee interview reports. Of these 54 applicants, 37 obtained a sufficient score to proceed to interview and were ranked based on their total score, and the top 24 applicants were interviewed. Applicants are ranked and allocated according to the number of training positions available, typically 6-11 per year. In 2019, 9 places were available with 7 male and 2 female successful applicants.

mechanisms to deal with complaints, discrimination, bullying, and harassment. Surgical logbook case numbers for 23 trainees completing training in 2016, 2017, and 2018 were collated and examined in an aggregated, de-identified form as a measure of adherence to accreditation standards. Of these trainees, 2 completed training in 4.5 years or less, 12 completed training in 5 years, 8 completed training in 6 years, and 1 required 7 years of clinical training. The outliers were removed from the data analysis so there was an accurate picture of the experience obtained by the "average" trainee (the 20 who completed training in 5 or 6 years). Additionally, written evaluations of the training experience were also sought from 2 trainees at the midpoint of their neurosurgical training, asking them to reflect on selection, training post quality, and limitations of the current system.

\section{Statistical Analysis}

Descriptive statistics including real numbers, ranges, and percentages were used. Data are not appropriate for advanced statistical analysis.

\section{Results \\ Change to Referee Reports Using Semistructured Interviews}

While an extremely time-consuming process, this method of obtaining referee reports by interview has resulted in a wider spread of scores and is more able to separate high- and low-scoring applicants than other components of the selection process. The number of applicants in 2019 and their performance in the selection process is shown in Table 4.

In 2014, during which pro forma written references were used, the average score was 33.7/35 (96\%, range 24.3-35), and this result was typical of previous years, with many applicants obtaining a near-perfect score. In 2015 , the 1st year the reference interview was utilized, the average score was $17.1 / 30$ (57\%, range $8-25)$. In subsequent years, the average scores were 17.5/30 (58\%, range 6.5-28.5 [2106]), 21.7/30 (72\%, range 4.8-30 [2017]), and $20.3 / 30$ (68\%, range 9-28.8 [2018]). In 2019, the most recent application interviews, the average score was $22.8 / 30$ (76\%, range 9.6-30). Thus, the references obtained via interview of three referees produce a wider spread of scores and a lower average score than written references, making them more suitable to separate applicants into high and lower performing groups.

\section{Accreditation of Training Posts and Trainee Experience}

There are currently 32 accredited training units in Australia (27), New Zealand (4), and Singapore (1), with a number accredited for more than 1 trainee to make a total of 56 training posts or positions. This number has increased in the last decade, from only 38 posts in 2009. The location of the 31 accredited training units in Australia and New Zealand is shown in Fig. 1. In 2018, two new applications for accreditation for training were denied on the basis of noncompliance with the standards outlined in Table 3, largely based on caseload. One unit not compliant on reaccreditation has lost its accreditation. Five units have been required to rectify deficiencies or have been given shorter periods off accreditation to allow for early reassessment.

\section{Trainee Experience}

Analysis of trainee logbook caseload data is one mechanism by which adherence of the training sites to accreditation standards can be analyzed and gives valuable information about the breadth and depth of the exposure of trainees. As described above, the logbooks of 20 average trainees, who had completed training in 2016, 2017, and 2018, were examined. Table 5 shows their caseload and casemix, which depicts the averaged operative experience of these trainees and shows that they more than fulfill the training requirements in accredited training posts (as outlined in Table 3), confirming the robust nature of at least this aspect of unit accreditation and the provision of adequate operative experience for trainees.

Additionally, from 2 trainees at the midpoint of their neurosurgical training, we sought written evaluations of the training experience, asking them to reflect on selection, training post quality, and limitations of the current system. A summary of their reflections on their training experience included the following:

Female, Second-Year Neurosurgical Trainee, Age 33

- An appreciation of the diversity of training due to the experience of multiple training units, resulting in a well-rounded trainee with the benefit of a larger professional network.

- An appreciation of the diversity of skill acquisition, 

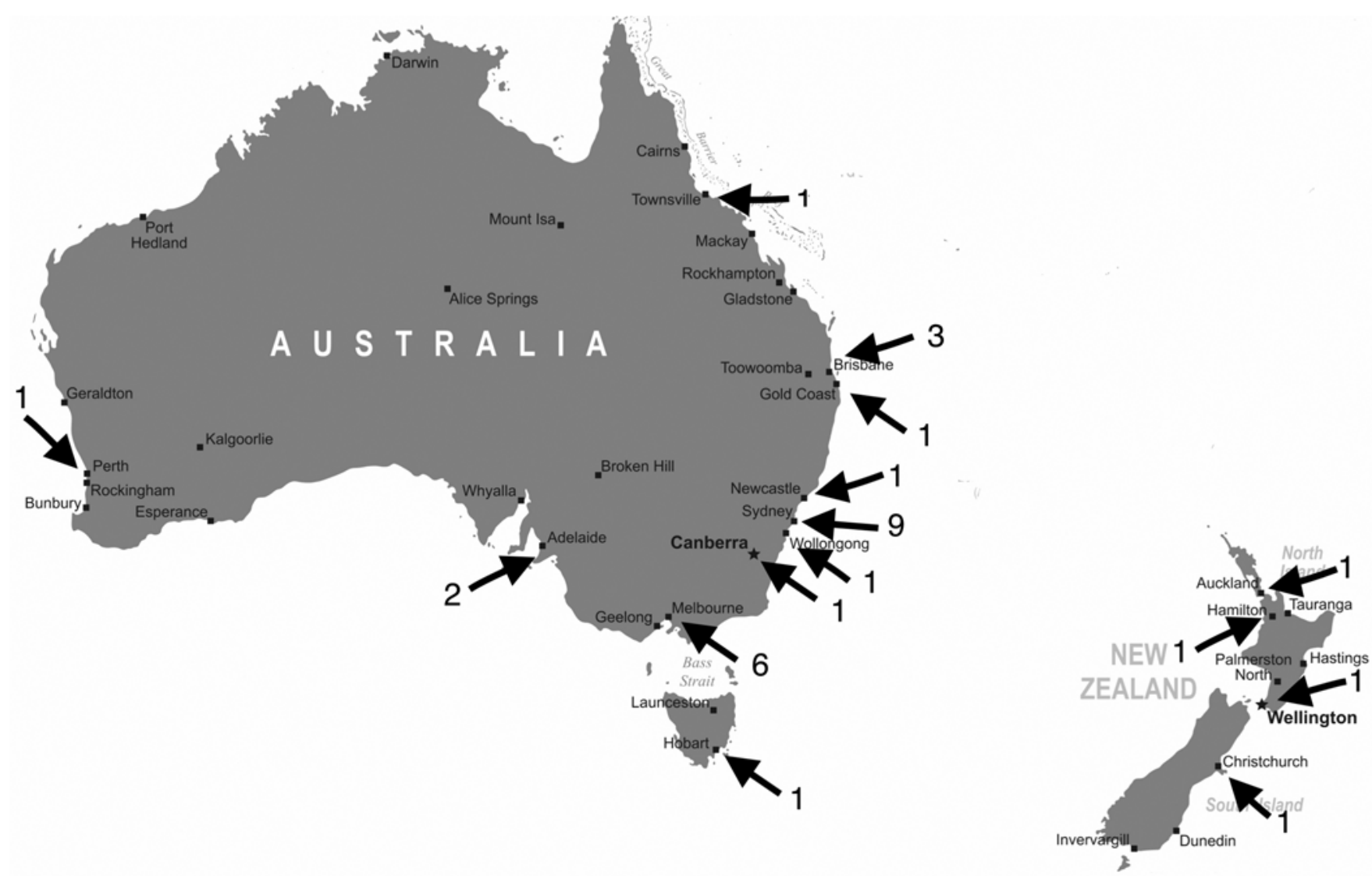

FIG. 1. The location of 31 accredited training units in Australia and New Zealand.

exposure to subspecialties, and varying departmental cultures to shape individual future practice.

- An expression of the logistical challenges of moving away from support networks, with resulting isolation, financial burden, relationship challenges (including for the spouse's career), and uncertainty regarding future postings.

Male, Third-Year Trainee Undertaking Full-Time Research, Age 34

- An appreciation of a relatively uniform standard of training not constrained to a particular hospital's strengths or subspecialty and also fostering relationships between hospitals to facilitate cooperative interests, such as research.

- An expression of the challenges of frequent relocation with the sudden loss of support networks critical during early training or the exit examination, as well as the impact on immediate family, including periods of separation.

- An expression of the stress of learning new hospital systems, policies, and practices.

Overall, the experience of a trainee in this system is highly individualized. Despite the challenges, many trainees report rotation between different training units to be a positive experience, citing the clinical exposure and a chance to work with different mentors as major advantages for their training. The experience has improved in recent times, with the establishment of a "home state," whereby the majority of training is performed across the hospitals located within that region. Although this reduces interstate or international relocation, it is still guaranteed to happen at least once during the training period, resulting in significant disruption, which can impact on the trainee and their immediate family.

\section{Discussion}

Overall, the binational, multiinstitutional training scheme has been very successful in improving the diversity, strength, and breadth of training for Australasian neurosurgeons. This success is evidenced by the caseload and casemix shown in Table 5, and the scheme is comparable or superior to programs in Canada, ${ }^{16}$ the United Kingdom, ${ }^{10}$ and Europe, ${ }^{13}$ many of which do not have similar constraints related to vast distances and a small, separated population. However, with the widely agreed upon benefits come challenges, as exemplified by the current trainee experience outlined in Results.

The first consideration, if training is to involve the hardship of moving between multiple institutions, including interstate or international moves, is to ensure excellent training, including a superior experience for the trainee. There is little in the literature to guide the accreditation of neurosurgical units apart from specific considerations for subspecialty training such as endovascular/cerebrovas- 
TABLE 5. Procedural logbook statistics for 20 average neurosurgical trainees completing their training in 5 or 6 years between 2016 and 2018 as a measure of adherence to casemix and caseload standards in accredited training units

\begin{tabular}{|c|c|c|c|c|c|c|c|c|c|}
\hline Case Type & Y1 & Y2 & Y3 & Y4 & Y5 & Primary Surgeon & Secondary Surgeon & Assistant & Total \\
\hline \multicolumn{10}{|l|}{ Adult cases } \\
\hline \multicolumn{10}{|l|}{ Cerebrovascular } \\
\hline Aneurysm clipping & 9 & 8 & 9 & 9 & 10 & 6 & 8 & 31 & 45 \\
\hline Arteriovenous malformation & 1 & 2 & 2 & 2 & 3 & 1 & 2 & 7 & 10 \\
\hline Endovascular procedure & 1 & 0 & 0 & 1 & 2 & 0 & 1 & 3 & 4 \\
\hline Intracranial hematoma evacuation & 2 & 2 & 2 & 2 & 2 & 7 & 1 & 2 & 10 \\
\hline Other & 3 & 0 & 1 & 2 & 2 & 1 & 1 & 6 & 8 \\
\hline Total & 16 & 12 & 14 & 16 & 19 & 15 & 13 & 49 & 77 \\
\hline Craniocervical junction total & 3 & 3 & 4 & 3 & 4 & 7 & 3 & 7 & 17 \\
\hline Epilepsy surgery total & 1 & 0 & 1 & 0 & 2 & 0 & 1 & 3 & 4 \\
\hline \multicolumn{10}{|l|}{ Hydrocephalus } \\
\hline Shunt procedures & 10 & 11 & 16 & 14 & 15 & 43 & 13 & 10 & 66 \\
\hline Endoscopic/other procedures & 2 & 2 & 2 & 2 & 1 & 4 & 2 & 3 & 9 \\
\hline Total & 12 & 13 & 18 & 16 & 16 & 47 & 15 & 13 & 75 \\
\hline Cerebral abscess total & 3 & 3 & 4 & 3 & 4 & 12 & 2 & 3 & 17 \\
\hline \multicolumn{10}{|l|}{ Pain } \\
\hline Trigeminal neuralgia & 3 & 3 & 3 & 4 & 4 & 6 & 2 & 9 & 17 \\
\hline Other & 1 & 2 & 1 & 2 & 2 & 2 & 1 & 5 & 8 \\
\hline Total & 4 & 5 & 4 & 6 & 6 & 8 & 3 & 14 & 25 \\
\hline \multicolumn{10}{|l|}{ Peripheral nerve } \\
\hline Carpal tunnel & 7 & 9 & 7 & 8 & 6 & 31 & 1 & 5 & 37 \\
\hline Other & 6 & 7 & 4 & 4 & 6 & 18 & 2 & 7 & 27 \\
\hline Total & 13 & 16 & 11 & 12 & 12 & 49 & 3 & 12 & 64 \\
\hline \multicolumn{10}{|l|}{ Spine } \\
\hline Lumbar discectomy & 21 & 25 & 23 & 23 & 21 & 57 & 13 & 43 & 113 \\
\hline Lumbar laminectomy & 24 & 26 & 23 & 24 & 23 & 70 & 16 & 34 & 120 \\
\hline Lumbar fusion & 15 & 20 & 19 & 20 & 28 & 27 & 31 & 44 & 102 \\
\hline Ant cervical discectomy fusion & 11 & 10 & 18 & 14 & 14 & 27 & 11 & 29 & 67 \\
\hline Other cervical procedures & 11 & 12 & 14 & 12 & 14 & 34 & 8 & 21 & 63 \\
\hline Thoracic procedures & 2 & 5 & 3 & 2 & 2 & 6 & 3 & 5 & 14 \\
\hline Tumor/abscess, other & 10 & 11 & 10 & 11 & 14 & 19 & 13 & 24 & 56 \\
\hline Total & 94 & 109 & 110 & 106 & 116 & 240 & 95 & 200 & 535 \\
\hline Functional total & 5 & 6 & 7 & 7 & 7 & 22 & 3 & 7 & 32 \\
\hline \multicolumn{10}{|l|}{ Trauma } \\
\hline Acute craniotomy & 11 & 11 & 11 & 9 & 12 & 42 & 6 & 6 & 54 \\
\hline Chronic subdural hematoma & 13 & 14 & 15 & 13 & 13 & 57 & 5 & 6 & 68 \\
\hline Cranioplasty/other & 8 & 6 & 6 & 4 & 6 & 21 & 4 & 5 & 30 \\
\hline Total & 32 & 31 & 32 & 26 & 31 & 120 & 15 & 17 & 152 \\
\hline \multicolumn{10}{|l|}{ Cranial tumor } \\
\hline Glioma & 14 & 19 & 17 & 16 & 19 & 37 & 16 & 32 & 85 \\
\hline Skull base/pituitary & 9 & 8 & 9 & 13 & 13 & 8 & 8 & 36 & 52 \\
\hline Meningioma & 9 & 10 & 10 & 9 & 10 & 17 & 9 & 22 & 48 \\
\hline Metastasis & 11 & 12 & 12 & 11 & 16 & 33 & 10 & 19 & 62 \\
\hline Other & 4 & 3 & 5 & 4 & 4 & 7 & 5 & 8 & 20 \\
\hline Total & 47 & 52 & 53 & 53 & 62 & 102 & 48 & 117 & 267 \\
\hline \multicolumn{10}{|l|}{ Minor/miscellaneous } \\
\hline EVD/ICP monitor & 14 & 15 & 11 & 10 & 11 & 59 & 1 & 1 & 61 \\
\hline Biopsy/other & 10 & 9 & 7 & 8 & 8 & 31 & 4 & 7 & 42 \\
\hline Total & 24 & 24 & 18 & 18 & 19 & 90 & 5 & 8 & 103 \\
\hline
\end{tabular}


» CONTINUED FROM PAGE 7

TABLE 5. Procedural logbook statistics for 20 average neurosurgical trainees completing their training in 5 or 6 years between 2016 and 2018 as a measure of adherence to casemix and caseload standards in accredited training units

\begin{tabular}{|c|c|c|c|c|c|c|c|c|c|}
\hline Case Type & Y1 & Y2 & Y3 & Y4 & Y5 & Primary Surgeon & Secondary Surgeon & Assistant & Total \\
\hline \multicolumn{10}{|l|}{ Adult cases (continued) } \\
\hline Total adult cases & 254 & 274 & 276 & 266 & 298 & 712 & 206 & 450 & 1368 \\
\hline \multicolumn{10}{|l|}{ Pediatric cases } \\
\hline Cerebrovascular & 0 & 1 & 1 & 1 & 0 & 0 & 0 & 3 & 3 \\
\hline Craniofacial & 1 & 2 & 4 & 3 & 1 & 1 & 2 & 8 & 11 \\
\hline Epilepsy surgery & 0 & 2 & 2 & 3 & 1 & 1 & 2 & 5 & 8 \\
\hline Hydrocephalus & 1 & 5 & 8 & 10 & 3 & 14 & 6 & 7 & 27 \\
\hline Endoscopy & 1 & 1 & 1 & 2 & 1 & 2 & 2 & 2 & 6 \\
\hline Spine & 1 & 4 & 5 & 6 & 1 & 3 & 3 & 11 & 17 \\
\hline Trauma & 1 & 3 & 4 & 3 & 1 & 8 & 2 & 2 & 12 \\
\hline Tumor & 1 & 5 & 5 & 8 & 2 & 3 & 5 & 13 & 21 \\
\hline Minor & 1 & 5 & 4 & 6 & 1 & 13 & 1 & 3 & 17 \\
\hline Total pediatric cases & 7 & 28 & 34 & 42 & 11 & 45 & 23 & 54 & 122 \\
\hline Logbook total & 261 & 302 & 310 & 308 & 309 & 757 & 229 & 504 & 1490 \\
\hline
\end{tabular}

Ant = anterior; EVD = external ventricular drain; ICP = intracranial pressure.

Data are reported as the average number of cases both for year of training (Y1-Y5) and for level of surgical involvement from primary surgeon to assistant.

cular surgery ${ }^{2}$ or spine neurosurgery, ${ }^{4}$ and there is little discussion of trainee welfare and satisfaction. The rigorous accreditation process outlined above appears to at least conform to best practice and is monitored through reaccreditation every 5 years as well as biannual trainee feedback, with scores across multiple years aggregated and released to the training unit to highlight deficiencies while maintaining trainee anonymity. Monitoring important metrics, such as operative experience, professional behavior, and participation in educational activities within the strict framework of national accreditation oversight, may avoid situations such as the recent high-profile media reports of "rogue" surgeons. Such individuals, including Chris Duntsch in the US (https://en.wikipedia.org/ wiki/Christopher_Duntsch) and Jayant Patel in Australia (https://en.wikipedia.org/wiki/Jayant_Patel), in retrospect, were often poorly trained and chronically underperforming but with a lack of oversight to identify deficiencies and nonparticipation in critical training activities.

The second consideration is trainee selection, with two chief problems identified in a centralized selection process. The first problem is the best method for selection, and the second is the lack of ownership and overall oversight of a trainee's career by any single institution. The method of selection usually involves a combination of $\mathrm{CV}$, examinations, references, interviews, and, occasionally, psychoanalytical or personality tests. This process is fraught, and there is no agreed upon standard. In a metaanalysis, Zuckerman et al. ${ }^{17}$ studied 21 articles evaluating 1276 resident applicants across five surgical subspecialties (no neurosurgical studies met the inclusion criteria). Of all the common pre-residency selection factors employed, objective standardized test scores correlated well with in-training and board examinations but correlated poorly with subsequent faculty evaluations of the trainee. Subjec- tive factors, such as aggregate rank scores, letters of recommendation, and athletic or musical talent, demonstrated only moderate correlations with future faculty evaluations. Similarly, Al Khalili et al. ${ }^{1}$ used a questionnaire based on the Electronic Residency Application Service (ERAS) guidelines with 3- or 4-point Likert scales. Of 46 neurosurgery residency program director respondents in August 2011, the most important factors in the selection process $(>0.3)$ were the interview process (mean $\pm \mathrm{SD}, 3.80 \pm$ 0.65), US Medical Licensing Examination (USMLE Step 1) scores $(3.58 \pm 0.54)$, and letters of recommendations $(3.56 \pm 0.54)$. However, the percentage of respondents reporting a high level of satisfaction with selected residents was only $60.9 \%$. In a multivariate analysis, predictors of long-term satisfaction with resident selection included less emphasis on letters of recommendation $(\mathrm{p}=0.037)$ and greater weight on applicant extramural activity $(\mathrm{p}=0.038)$. Thus, the NSA efforts to improve the referee process as described above are timely and address a well-recognized deficiency. In particular, the referee reports have a strong emphasis on identifying proficiency in nontechnical skills, which are increasingly seen as critical to neurosurgery practice. This is evidenced by initiatives such as Neurosurgery Boot Camp, which includes training in professionalism and communications skills as well as traditional skills-based teaching. ${ }^{9}$ The success of the in-depth referee interviews, however, will only become evident with future analysis of training completion and performance.

The second problem in a centralized selection process is the lack of "ownership" of centrally selected trainees allocated to a training unit with which they have no ongoing mentoring or supportive relationship. This is a recognized deficiency with the Australasian system and may lead to the movement of underperforming trainees to the next training unit as a path of least resistance, thus avoiding 
the more difficult and sometimes adversarial or litigious path of giving genuine negative feedback, refusing to give a reference, or even failing a trainee in a placement. In addition, there are implications for future employment. Consider, for example, an "orphan" graduate with no ties to a specific hospital, without a "home" hospital, which is traditionally the place of first postgraduate employment in Australia and New Zealand. Solutions to this identified problem are not clear, but the creation of smaller training networks or home units are suggested.

Future challenges will involve addressing the deficiencies identified above, particularly in the face of an ever-increasing number of applicants to neurosurgery training in Australia and New Zealand who are older and more likely to have a professional partner and children. For this group, constant moves are an increasing hardship, but we must find solutions that do not dilute the excellent breadth and depth of neurosurgical training currently achieved.

\section{References}

1. Al Khalili K, Chalouhi N, Tjoumakaris S, Gonzalez LF, Starke RM, Rosenwasser R, et al: Programs selection criteria for neurological surgery applicants in the United States: a national survey for neurological surgery program directors. World Neurosurg 81:473-477.e2, 2014

2. Alamri A, Chari A, McKenna G, Kamaly-Asl I, Whitfield PC: The evolution of British neurosurgical selection and training over the past decade. Med Teach 40:610-614, 2018

3. Bernardo A: Virtual reality and simulation in neurosurgical training. World Neurosurg 106:1015-1029, 2017

4. Boszczyk BM, Mooij JJ, Schmitt N, Di Rocco C, Fakouri $\mathrm{BB}$, Lindsay KW: Spine surgery training and competence of European neurosurgical trainees. Acta Neurochir (Wien) 151:619-628, 2009

5. Chari A, Jamjoom AA, Edlmann E, Ahmed AI, Coulter IC, Ma R, et al: The British Neurosurgical Trainee Research Collaborative: five years on. Acta Neurochir (Wien) 160:23-28, 2018

6. Choi BD, DeLong MR, DeLong DM, Friedman AH, Sampson JH: Impact of PhD training on scholarship in a neurosurgical career. J Neurosurg 120:730-735, 2014

7. Davidson B, Alotaibi NM, Guha D, Amaral S, Kulkarni AV, Lozano AM: Studying behaviors among neurosurgery residents using Web 2.0 analytic tools. J Surg Educ 74:10881093, 2017

8. Day AL, Siddiqui AH, Meyers PM, Jovin TG, Derdeyn CP, Hoh BL, et al: Training standards in neuroendovascular surgery: program accreditation and practitioner certification. Stroke 48:2318-2325, 2017
9. Fontes RB, Selden NR, Byrne RW: Fostering and assessing professionalism and communication skills in neurosurgical education. J Surg Educ 71:e83-e89, 2014

10. Lindsay KW: Neurosurgical training in the United Kingdom and Ireland: assessing progress and attainment. Neurosurgery 50:1103-1113, 2002

11. Morgan MK, Clarke RM, Lyon PM, Weidmann M, Law A, Laidlaw J, et al: The neurosurgical training curriculum in Australia and New Zealand is changing. Why? J Clin Neurosci 12:115-118, 2005

12. Pelargos PE, Nagasawa DT, Lagman C, Tenn S, Demos JV, Lee SJ, et al: Utilizing virtual and augmented reality for educational and clinical enhancements in neurosurgery. J Clin Neurosci 35:1-4, 2017

13. Reulen HJ, März U: 5 years' experience with a structured operative training programme for neurosurgical residents. Acta Neurochir (Wien) 140:1197-1203, 1998

14. Stienen MN, Schaller K, Cock H, Lisnic V, Regli L, Thomson $\mathrm{S}$ : eLearning resources to supplement postgraduate neurosurgery training. Acta Neurochir (Wien) 159:325-337, 2017

15. Suri A, Patra DP, Meena RK: Simulation in neurosurgery: past, present, and future. Neurol India 64:387-395, 2016

16. Tso MK, Dakson A, Ahmed SU, Bigder M, Elliott C, Guha $\mathrm{D}$, et al: Operative landscape at Canadian neurosurgery residency programs. Can J Neurol Sci 44:415-419, 2017

17. Zuckerman SL, Kelly PD, Dewan MC, Morone PJ, YengoKahn AM, Magarik JA, et al: Predicting resident performance from pre-residency factors: a systematic review and applicability to neurosurgical training. World Neurosurg 110:475-484.e10, 2018

\section{Disclosures}

The authors report no conflict of interest concerning the materials or methods used in this study or the findings specified in this paper.

\section{Author Contributions}

Conception and design: Drummond, Davies. Acquisition of data: Drummond, McAlpine, Jones, Gull. Analysis and interpretation of data: Drummond, Hunn, McAlpine, Jones, Gull. Drafting the article: Drummond, Hunn, McAlpine, Jones. Critically revising the article: all authors. Reviewed submitted version of manuscript: all authors. Administrative/technical/material support: Gull.

\section{Correspondence}

Katharine J. Drummond: The Royal Melbourne Hospital, Melbourne, Victoria, Australia. kate.drummond@mh.org.au. 